Review Article

\title{
Omega-3 Polyunsaturated Fatty Acids Intake to Regulate Helicobacter pylori-Associated Gastric Diseases as Nonantimicrobial Dietary Approach
}

\author{
Jong-Min Park, Migyeong Jeong, Eun-Hee Kim, Young-Min Han, \\ Sung Hun Kwon, and Ki-Baik Hahm \\ CHA Cancer Prevention Research Center, CHA Cancer Institute, CHA Bio Complex, Seongnam 463-400, Republic of Korea \\ Correspondence should be addressed to Ki-Baik Hahm; hahmkb@cha.ac.kr
}

Received 26 September 2014; Revised 20 December 2014; Accepted 15 January 2015

Academic Editor: Karsten Weylandt

Copyright (C) 2015 Jong-Min Park et al. This is an open access article distributed under the Creative Commons Attribution License, which permits unrestricted use, distribution, and reproduction in any medium, provided the original work is properly cited.

Omega-3 polyunsaturated fatty acids (n-3 PUFAs), commonly eicosapentaenoic acid (EPA) and docosahexaenoic acid (DHA), have been acknowledged as essential long-chain fatty acids imposing either optimal health promotion or the rescuing from chronic inflammatory diseases such as atherosclerosis, fatty liver, and various inflammatory gastrointestinal diseases. Recent studies dealing with EPA and DHA have sparked highest interests because detailed molecular mechanisms had been documented with the identification of its receptor, G protein coupled receptor, and GPR120. In this review article, we have described clear evidences showing that n-3 PUFAs could reduce various Helicobacter pylori- (H. pylori-) associated gastric diseases and extended to play even cancer preventive outcomes including $H$. pylori-associated gastric cancer by influencing multiple targets, including proliferation, survival, angiogenesis, inflammation, and metastasis. Since our previous studies strongly concluded that nonantimicrobial dietary approach for reducing inflammation, for instance, application of phytoceuticals, probiotics, natural products including Korean red ginseng, and walnut plentiful of n-3 PUFAs, might be prerequisite step for preventing $H$. pylori-associated gastric cancer as well as facilitating the rejuvenation of precancerous atrophic gastritis, these beneficial lipids can restore or modify inflammation-associated lipid distortion and correction of altered lipid rafts to send right signaling to maintain healthy stomach even after chronic $H$. pylori infection.

\section{Introduction}

Gastric cancer is the fourth most common cancer and the second leading cause of mortality worldwide. Almost twothirds of affected individuals will die from their disease. Gastric carcinogenesis has a multifactorial etiology. Helicobacter pylori (H. pylori) infection is the most important risk factor for both gastritis and gastric carcinoma [1]. Host genotype, bacterial virulence factors, and environmental conditions increase the risk of gastric cancer [2]. Gastric cancer develops due to $H$. pylori infection and chronic inflammation in a slow pace. It begins by an $H$. pylori infection that progresses to chronic active gastritis. H. pylori is adapted to survive in the acidic gastric environment. Bacterial adhesion to gastric epithelial cells induces inflammation that results in the recruitment of neutrophils followed by B and T lymphocytes, macrophages, and plasma cells. As a result, reactive oxygen and nitrogen species are produced, which are involved in gastric epithelial cell damage and carcinogenesis. H. pylori is considered to be the initiator of a chronic inflammatory response that summons bone marrow-derived cells to the gastric mucosa, thereby directly contributing to development of gastric cancer. Main virulence factors of $H$. pylori for the induction of mucosal inflammation are cytotoxin-associated gene (cag) pathogenicity island- (PAI-) encoded virulence factors, such as cytotoxin-associated antigen (CagA) protein, vacuolating toxin-A (VacA), blood group antigenbinding adhesion (BabA), and outer inflammatory protein (OipA). Under the influence of various environmental and host factors, chronic active gastritis may in turn evolve into atrophic gastritis and intestinal metaplasia. Metaplasia undergoes further genomic and phenotypic changes, 

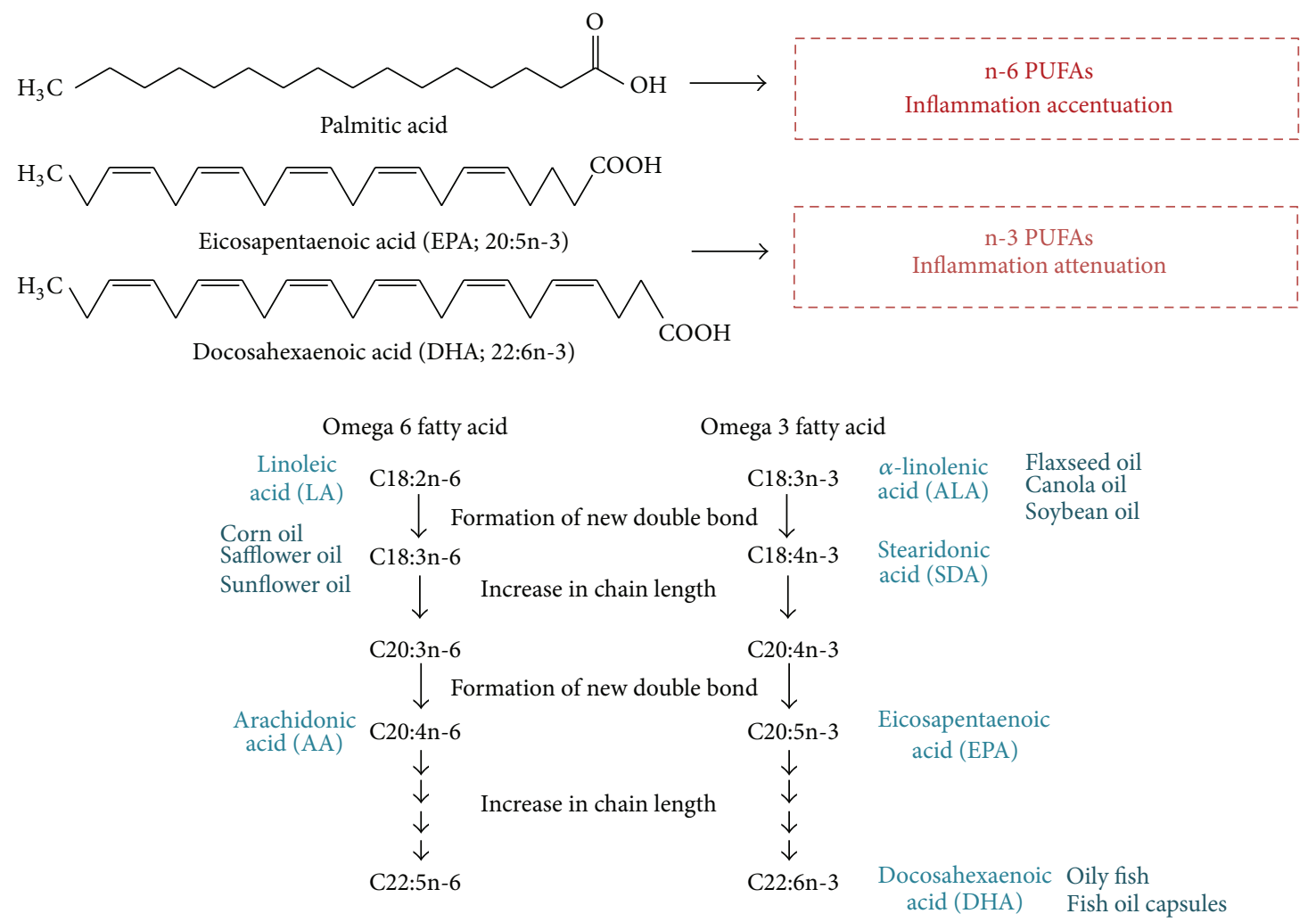

FIgURE 1: Essential n-3 PUFAs contributed to anti-inflammatory action based on their unsaturated bonds.

resulting in gastric dysplasia and finally adenocarcinoma [3].

Omega-3 (n-3) polyunsaturated fatty acids [n-3 PUFAs, eicosapentaenoic acid (EPA 20:5n-3), and docosahexaenoic acid (DHA 22:6n-3)] are the long-chain PUFAs, which are essential fatty acids as they can be synthesized by mammals from other dietary precursors containing n-3 PUFAs. They are sufficiently found in fish. Fatty acids are key nutrients affecting early growth and development and preventing chronic disease in later life [4]. PUFAs that contain more than one carbon double bond are divided into two major classes, namely, n-6 and n-3 (Figure 1). Several lipid metabolites can be made from these PUFAs. Linoleic acid (LA 18:2n6) is a representative $n-6$ PUFA, which is the precursor of arachidonic acid (AA 20:4n-6) that is involved in inflammation, inducing cardiovascular diseases, diabetes, cancer, and age-related diseases [4]. $\alpha$-Linolenic acid (ALA), EPA, and DHA are important n-3 PUFAs that are required for human to remain healthy. Several studies suggest that $n-3$ PUFAs are capable of preventing diseases due to their antioxidant and anti-inflammatory characteristics. Particularly, n-3 PUFAs are shown to have protective effects against chronic inflammatory diseases such as cardiovascular diseases $[5,6]$, rheumatoid arthritis [7], diabetes [8], other autoimmune diseases $[9,10]$, and cancer $[11,12]$. However, scant evidence exists for their role against $H$. pylori infection despite their known favorable effects.

Increased western-style fat consumption in the Eastern world (high in n-6 to n-3 PUFA ratio) is associated with the development of esophageal, breast, gastric, colon, and pancreatic and prostate cancers. Yet, n-3 PUFAs have multiple beneficial antitumor functions that are shown to change the malignant growth in a number of studies [13]. Studies on the fatty acid level in patients with bladder, pancreatic, lung, and esophageal cancer have shown low concentrations of plasma n-3 PUFAs, ranging from 55 to $88 \%$, in comparison with healthy individuals [14-16]. Epidemiologic studies suggest that a high n-3 to n-6 PUFA ratio may be the optimal strategy to decrease cancer risk [17]. A solid epidemiologic study added the evidence that consumption of n-3 PUFAs appears to protect against the development of hepatocellular carcinoma even among patients with $\mathrm{HBV}$ and/or HCV infection [18]. A possible protective effect of dietary n-3 PUFAs against prostate cancer has been reported [19]. Fasano et al. [20] reviewed many in vivo and in vitro studies and found that n-3 PUFAs have antitumor properties against lung cancer. Then, how about the role of n-3 PUFAs against $H$. pylori infection?

\section{Omega-3 Polyunsaturated Fatty Acids (n-3 PUFAs) and Inflammation}

n-3 PUFAs are essential for health. They are widely studied for their roles in human health and disease [21]. Recently, they are shown to be effective in treating and preventing various diseases [22]. n-3 PUFAs have a therapeutic role against inflammatory diseases such as rheumatoid 
arthritis (RA), inflammatory bowel disease (IBD), asthma, and cardiovascular and neurodegenerative diseases [23-25]. A number of animal and human studies have provided convincing evidence for the anti-inflammatory effects of $n-3$ PUFAs. n-3 PUFAs are beneficial as a dietary supplement in RA by reducing the level of AA-derived eicosanoids and inflammatory cytokines, which include interleukin-1, interleukin-2, interleukin-6, and interleukin-8, as well as TNF- $\alpha$ and $\mathrm{LTB}_{4}$, promoting anti-inflammatory activities $[26,27]$. Moreover, n-3 PUFAs have an NSAID-sparing effect in RA by decreasing pain and gastroduodenal damage [28, 29]. Dietary n-3 PUFA intake is associated with a decreased risk of developing Crohn's disease (CD) and ulcerative colitis (UC) by modulation of inflammatory events such as reducing $\mathrm{LTB}_{4}, \mathrm{PGE}_{2}$, and thromboxane $\mathrm{B}_{2}$ production [30-32]. n-3 PUFA administration has been shown to exert beneficial effects on animal model with induced lung inflammation or acute injury through decreasing the eosinophilic infiltration into the lung and improving the lung function $[22,33]$. Fat-1 transgenic mice with elevated n-3 PUFAs levels have lower concentrations of proinflammatory cytokines and higher concentrations of protectin D1 and resolvin E1 in their lungs [34]. Fish oil with n-3 PUFAs decreases the incidence of atherosclerotic lesions and frequency of cardiac arrest contributing to a reduction in overall mortality in patients at risk of cardiovascular diseases [35-37]. n-3 PUFAs prevented the functional and anatomical changes in diabetic neuropathy, reduced oxidative damage, prevented learning disability in brain injury, and reduced the accumulation of $\beta$-amyloid in Alzheimer's disease [38-40].

Overall, supplementation of n-3 PUFAs directly reduces the production of inflammatory eicosanoids by replacing AA as an eicosanoid substrate and inhibiting AA metabolism by changing the cell membrane phospholipid fatty acid composition. n-3 PUFAs indirectly reduce the production of cytokines, reactive oxygen species (ROS), and adhesion molecules by altering the expression of inflammatory genes. This is achieved by intervening in the inflammatory signaling cascade, which include disruption of lipid rafts, activation of the anti-inflammatory transcription factor peroxisome proliferator-activated receptor $\gamma$, and binding to the $G$ protein-coupled receptor GPR120 [23, 41]. Moreover, n-3 PUFAs can partially inhibit the inflammatory processes that involve leukocyte chemotaxis and T-helper 1 lymphocyte reactivity [41]. These properties suggest that n-3 PUFAs could have a therapeutic role in inflammatory diseases.

\section{The Effect of n-3 PUFAs on Inflammation- Based Gastric Cancers}

Most GI cancers including esophageal, stomach, and colorectal cancers have a natural history of multistep transition from precursor lesions to malignant lesions, over which inflammation, adenoma formation, and dysplastic changes prevail [42]. Therefore, GI cancers usually go through a premalignant lesion before development of the invasive cancer. Examples include Barrett's esophagus before esophageal cancer, chronic atrophic gastritis, and intestinal metaplasia before gastric cancer and adenoma or dysplasia in the setting of chronic ulcerative colitis before colon cancer. Since western diet contains disproportionally high amounts of n-6 PUFAs and low amounts of n-3 PUFAs (high n-6 to n-3 PUFA ratio), n-3 PUFAs-rich diets could become cancer preventive measures by affecting several stages of GI cancer development. Here, we introduce more carcinogenic detail regarding the interplay of inflammation and n-3 PUFAs intake.

Gastric cancer is the fourth most common cancer worldwide and almost two-thirds of affected individuals will die of their disease. Despite national efforts, 20 out of 100,000 Koreans die from gastric cancer. A number of studies investigating the association between n-3 PUFAs and gastric diseases suggest a protective effect for $n-3$ PUFAs in gastric cancer. Recently, Correia et al. [43] showed that DHA inhibits $H$. pylori growth in vitro and mice gastric mucosa colonization. It has been proposed that PUFAs hold an inhibitory effect on bacterial growth via disruption of cell membrane leading to bacteria lysis [44]. Mohammed et al. [45] showed that n-3 PUFAs reduce iodoacetamide-induced gastritis in rats by decreasing malondialdehyde (MDA), gastrin and nitric oxide (NO), and normalizing mucosal glutathione. Erythrocyte composition of DHA is found to be negatively associated with the risk of well-differentiated gastric adenocarcinoma [46]. n-3 PUFAs-rich diet delayed tumor growth in a mouse xenograft model of gastric cancer [47]. Another in vitro study showed that n-3 PUFAs inhibit macrophage-enhanced gastric cancer cell migration and attenuate matrix metalloproteinase- (MMP-) 10 expression through ERK and STAT3 phosphorylation [48] and inhibit the growth of human gastric carcinoma via apoptosis [49]. Moreover, n-3 PUFAs are beneficial for preventing oxidative stress-induced apoptosis by inhibiting apoptotic gene expression and DNA fragmentation of gastric epithelial cells [50]. DHA induces apoptosis of gastric cancer cells by inducing the expression of apoptotic genes [51]. Although a large body of literature spanning numerous cohorts from many countries with different demographic characteristics does not provide evidence to suggest a significant association between n-3 PUFAs and the incidence of stomach cancer [52], precise studies are required to investigate the antitumor properties of $n-3$ PUFAs in the stomach.

\section{Molecular Mechanisms of n-3 PUFAs Effect against $H$. pylori Infection}

4.1. Attenuation of $H$. pylori-Associated Inflammation. $H$. pylori is clever as it changes n-6 PUFAs metabolism to foster gastric environment or to enhance gastric inflammation. Nakaya et al. [53] studied the formation of n-6 PUFAs from LA in rat gastric mucosal cells after $H$. pylori infection. They found that addition of LA leads to an increase in the composition of AA, LA, and $\mathrm{PGE}_{2}$. Cyclooxygenase-2 (COX2) expression is induced in $R G M-1$ cells by addition of LA. $H$. pylori culture broth filtrates had decreased LA and increased AA compositions. Moreover, after incubation with $H$. pylori culture filtrates, $\mathrm{PGE}_{2}$ concentrations were higher than controls. Thus, $H$. pylori infection can enhance $\mathrm{PGE}_{2}$ 
synthesis and accelerate n-6 PUFAs metabolism in gastric mucosal cells, which can make the gastric mucosal barrier more fragile. On the other hand, since essential dietary fatty acids bestow gastroduodenal mucosal protection [54], n-3 PUFAs can provide efficient gastroprotection against $H$. pylori, drug-induced and stress-induced gastric mucosal damages [55]. These effects were first observed in 1987 when the link between low levels of PUFAs and H. pylori-associated duodenal ulcer was shown in an interventional dietary study [56]. Recent studies have shown anti-inflammation potential propertied for n-3 PUFAs [57, 58]. n-3 PUFAs suppressed the activation of EGFR, PKC $\delta, \mathrm{MAPK}, \mathrm{NF}-\kappa \mathrm{B}$, and AP-1 in $H$. pylori-infected gastric epithelial AGS cells. n-3 PUFAs are beneficial for prevention of $H$. pylori-associated gastric inflammation by inhibiting proinflammatory IL-8 expression [57]. AGS cells that were infected with DHA pretreated $H$. pylori showed a 3 -fold reduction in IL-8 production and a decrease in COX-2 and inducible nitric oxide synthase (iNOS) [58]. However, the other side of the n-3 PUFAs coin is shown in gastrointestinal inflammations, where worse effects are reported with n-PUFAs despite the above-mentioned positive effects. For example, Woodworth et al. [59] and Butler and Yu [60] studied the effect of dietary fish oil enriched with DHA on reduction of experimentally induced colitis and colon cancer risk. In their experiments, they infected Smad3 null mice with $H$. hepaticus to induce colitis. They observed mild colitis 4 weeks after infection, but paradoxically, mice fed with isocaloric diets modified to include corn oil, sunflower oil, or DHA (as the fatty acid source) developed severe colitis and adenocarcinoma with DHA after 8 weeks. They concluded that DHA-fed mice may be less equipped to mount a successful response to $H$. hepaticus infection (increasing colon cancer risk), supporting the need to establish a tolerable upper limit for DHA intake particularly in the setting of chronic inflammation. In another study, DHA-fed Smad3 knockout mice had significantly higher levels of plasma IL-5, IL-13, and IL-9 (Th2-biasing cytokines) and cecal IgA compared with control, leading to the emerging concept that fish oil might enhance B cell function in vivo to aggravate an existing inflammatory response [61]. A proposed molecular mechanism by which DHA exerts its effects is modification of lipid raft organization [62]. Regarding the discrepancy in the efficacy of n-3 PUFAs, Rockett et al. [63] demonstrated that a physiologically relevant dose of n-3 PUFAs increases the size of B cell rafts, GM1 surface expression, and membrane molecular order upon cross-linking. Increasing lipid raft size with fish oil was accompanied by changes in innate and adaptive function. Other factors should also be exploited to use n-3 PUFAs as a safer rescue agent against $H$. pylori infection in future.

\subsection{Antimicrobial Activity against $H$. pylori: A Direct Effect} on the Bacteria. Eradication of $H$. pylori with a proton pump inhibitor-based triple therapy is currently the treatment of choice for $H$. pylori infection. However, it has a success rate of $80-90 \%$. Treatment failure and contraindications in some patients are common. Furthermore, rapidly emerging drug resistance in $H$. pylori strains during treatment with different antibiotics is a major obstacle for successful eradication. Due to the prevalence of antibiotic-resistant $H$. pylori strains, there is an increasing effort in seeking other safe and effective compounds that inhibit $H$. pylori growth. Recent studies have shown that n-3 PUFAs have anti- $H$. pylori potentials. PUFAs significantly inhibit $H$. pylori's growth [44]. A very recent in vitro and in vivo investigation [43] clearly showed that n-3 PUFAs inhibit H. pylori growth in vitro and its colonization in mice gastric mucosa in vivo. This study is implicated in therapy and alleviation of $H$. pylori-induced inflammation. Since drug-resistant $H$. pylori strains and noncompliance to therapy are the major causes of $H$. pylori eradication failure, n-3 PUFAs could be used to lower the recurrence rate of infection in combination with standard triple therapy. This can prohibit $H$. pylori's ability to colonize the mouse stomach. DHA has also been shown to decrease H. pyloris growth and associated inflammation. Anti-H. pylori effects of DHA are associated with changes in bacterial morphology, metabolism, and alteration of the composition of outer membrane proteins, which ultimately reduces the adhesion of bacteria and the burden of $H$. pylori-related inflammation [58]. In contrast to the in vitro bacteriostatic and bactericidal efficacy of n-3 PUFAs, Meier et al. [64] showed that fish oil is less effective than metronidazole, in combination with pantoprazole and clarithromycin, for $H$. pylori eradication.

4.3. Imposing Restorative Mechanism and Reducing H. pyloriInduced Cytotoxicity. Regeneration-promoting role of $\mathrm{n}-3$ PUFAs is well acknowledged in several medical fields, namely, liver regeneration [65], wound healing [66], bone preservation [67, 68], burn [69], endothelial regeneration [70], cellular resolution of inflammation [71], recovery from nerve injury [72], and regeneration from previous intestine surgery [73]. n-3 PUFAs are shown to prevent acute liver failure and promote liver regeneration in rats by protecting the structure of the sinusoidal endothelial cells (SEC) in the acute phase after hepatectomy along with phosphorylation of the STAT3 and Akt [74]. A large number of animal and human studies have reported a positive n-3 PUFAs effect on increased bone formation, reduced bone resorption, and protection from osteoporosis [68]. Improvement in bone health is achieved by attenuation of mediators of osteoclastogenesis, namely, PGE2, COX-2, IL1- $\beta, \mathrm{TNF} \alpha$, and $\mathrm{NF}-\kappa \mathrm{B}$, in particular via the $\mathrm{E}$ (EPA derived) and $\mathrm{D}$ (DHA derived) series of resolvins. Eicosapentaenoic acid-derived resolvin E1 (RvE1) enhances resolution of inflammation, prevents bone loss, and induces bone regeneration [67]. RvE1 modulates osteoclast differentiation and bone remodeling by direct actions on bone. It rescues osteoprotegerin (OPG) production and restores a favorable $\mathrm{NF}-\kappa \mathrm{B}$ ligand/OPG receptor-activator ratio along with known anti-inflammatory and proresolving actions. RvD2 effectively prevents thrombosis of the deep dermal vascular network (DDVN) in early phases of burn injury. Therefore, it reduces secondary tissue damage and promotes long-term survival of deep dermal components after the initial thermal insult [69]. Alexander et al. have shown improved protein synthesis after burn injury in rats receiving n-3 PUFAs supplementation [75]. Interestingly, in 
a model of corneal nerve regeneration after surgery, it has been shown that DHA has strong proregenerative effects in combination with pigment epithelial growth factor. The authors hypothesized that this may involve formation of neuroprotectin D1 (a DHA metabolite) [76]. Dietary supplementation with n-3 PUFAs improved colonic anastomoses healing [73]. n-3 PUFAs enhance the colonic wound healing in a rat model. Finally, n-3 PUFAs may prompt faster resolution of inflammation within the wound microenvironment, which leads to facilitated regeneration and reepithelialization. A small randomized controlled trial evaluated a formula supplemented with fish oil in patients with pressure ulcers and noted decreased progression of pressure ulcers in those receiving fish oil supplementation [77].

There is growing evidence that the diverse biological roles of n-3 PUFAs contribute to their regenerative actions against chronic inflammatory disease. This could effectively help resolve the inflammation and promote a transition from the inflammatory to the proliferative and remodeling phases of wound healing [78]. n-3 PUFAs can be incorporated into membrane phospholipids, which causes reduced membrane fluidity. It could be associated with lipid raft assembly and function. Lipid rafts are cholesterol-rich microdomains at the host cell surface and are required for NF- $\kappa \mathrm{B}$-dependent responses to $H$. pylori. Recently, several studies have suggested that n-3 PUFAs can be converted into bioactive mediators, including resolvins, which exert inflammation-resolving properties via counterregulation of lipid mediators including proinflammatory leukotriene (LTs) and prostaglandin (PGs). Thus, our group investigated long-term treatment of n-3 PUFAs in an $H$. pylori-infected animal model and found that n-3 PUFAs administration ameliorated $H$. pylori-induced gastric inflammation and atrophic gastritis. It also reduced the incidence of $H$. pylori-associated gastric carcinogenesis (unpublished data). We could be the first group to document the rejuvenating action of n-3 PUFAs on $H$. pylori-associated atrophic changes in stomach. As the use of n-3 PUFAs for treatment of $H$. pylori-induced GI disorders is rapidly moving into clinical settings with more studies explaining the mechanism of action, detailed randomized controlled trials are required to obtain strong evidence for the incorporation n3 PUFAs into the therapeutic armamentarium in near future.

4.4. H. pylori-Induced Oxidative Stress and the Scavenging Action of n-3 PUFAs. Although limited reports are available on the antioxidative action of n-3 PUFAs against $H$. pylori infection, this antioxidative feature is well known in cardiovascular and neurological fields. A very recent high impact evidence came from Lluís et al. [79] showing that a diet of $1: 1$ ratio of EPA/DHA improves many oxidative stress parameters like superoxide dismutase (SOD) and glutathione peroxidase (GPx) in erythrocytes, plasma antioxidant capacity, and cardiovascular risk factors (glycated hemoglobin) relative to the other diets. Avramovic et al. [80] showed beneficial effects of n-3 PUFAs on the oxidative stress in brain tissue, improving neurogenesis and neuroplasticity [81]. Regarding antioxidative effects of n-3 PUFAs against $H$. pylori infection, we investigated the direct scavenging action of EPA using electron spin resonance and found significant antioxidative actions against hydroxyl and superoxide radicals.

\subsection{Proposed Mechanisms of n-3 PUFAs Cancer Prevention} against $H$. pylori-Associated Carcinogenesis. n-3 PUFAs can suppress the anti-inflammatory-related function of $\mathrm{T}$ lymphocytes and antigen presenting cells (APCs). The mechanism by which DHA modifies lymphocyte function is changing the organization of sphingolipid/cholesterol lipid raft membrane domains. Two contradictory models have been proposed to explain how DHA exerts its effects by changing the raft organization. One is the cellular model, which proposed that DHA is directly incorporated into the lipid rafts and changes the protein activity to suppress the lymphocytic functions. The other suggests modification of lymphocytic function by formation of nanometer scale DHArich domains, which disrupts the optimal raft-dependent clustering of proteins necessary for initial signaling. A biophysical DHA-containing phospholipid membrane model showed that unique nonraft membrane domains are formed that are organizationally distinct from lipid rafts. This alters the conformation and/or lateral organization of lymphocyte proteins [82]. Based on n-3 PUFAs effects on lymphocytes and modulation of inflammation, n-3 PUFAs, especially EPA or DHA, are shown to have multiple antigastric-tumor actions. Our current knowledge of the antitumor activity of n-3 PUFAs has been comprehensively reviewed elsewhere $[12,19,83]$. Recently, Stephenson et al. [13] have reviewed more recent underlying mechanisms of antitumor properties of n-3 PUFAs. n-3 PUFAs inhibit growth signal transduction. They appear to downregulate epidermal growth factor receptor (EGFR), protein kinase $\mathrm{C}(\mathrm{PKC}), \mathrm{Ras}, \mathrm{NF}-\kappa \mathrm{B}$, and insulin-like growth factor (IGF), which are important cellsignaling mediators often found to be elevated in cancer. n3 PUFAs also induce cancer cell apoptosis via modulation of peroxisome proliferator-activated receptors (PPARs), Bcl2 family, and NF- $\kappa \mathrm{B}$ cell signaling. They decrease sprouting angiogenesis by suppressing vascular endothelial growth factor- (VEGF-) and platelet derived growth factor- (PDGF-) stimulated endothelial cell proliferation, migration and tube formation through inhibition of MMPs via NO production, and NF- $\kappa \mathrm{B}$ and $\beta$-catenin cell signaling. Moreover, n-3 PUFAs decrease cell-cell adhesion via downregulation of Rho-GTPase (inhibits cytoskeleton reorganization) and reduction in intercellular adhesion molecule- (ICAM-) 1 and vascular cell adhesion molecule- (VCAM-) 1 expression.

Cockbain et al. [12] have proposed four main antitumor actions for n-3 PUFAs, namely, (1) modulation of COX activity, (2) alteration of membrane dynamics and cell surface receptor function, (3) increase in cellular oxidative stress leading to cytotoxicity, and (4) enhancement of anti-inflammatory lipid mediators. In mechanistic details, n-3 PUFAs can act as alternative substrates for COX-2 (instead of AA) leading to a reduction in formation of protumorigenic " 2 -series" $\mathrm{PGs}\left(\mathrm{PGE}_{2}\right)$ in several cell types. They also bind the substrate channel of COX-2 and inhibit COX-2 activity. In addition, incorporation of n-3 PUFAs into the cell membrane alters the fluidity, structure, and/or 
function of lipid rafts or caveolae. Localization of cell surface receptors such as G protein-coupled receptors (GPCRs), tolllike receptors (TLRs), and epidermal growth factor receptor (EGFR) in lipid rafts is believed to be crucial for downstream receptor signaling, which controls proliferation and apoptosis.

Rockett et al. [84] showed that membrane raft organization is more sensitive to disruption by n-3 PUFAs than the nonraft organization. n-3 PUFAs can also have an antitumor effect via alteration of the cellular redox state. They can increase ROS due to being highly peroxidizable. Therefore, n-3 PUFAs can induce cancer cell apoptosis via elevation of intracellular ROS levels. Lastly, n-3 PUFAs can be metabolized into novel anti-inflammatory lipid mediators including resolvins, protectins, and maresins. Resolvins exhibit antineoplastic activity via anti-inflammatory and inflammation resolution features in animal models of acute inflammation. Nuclear factor erythroid 2-related factor $2(\mathrm{Nrf} 2)$ is a redoxsensitive master regulatory transcriptional factor that plays an important protective role in cells by regulating cellular redox balance [85]. Recently, it was reported that n-3 PUFAs can activate Nrf2 and induced Nrf2-directed gene expression $[86,87]$. They can suppress lipopolysaccharide-induced inflammation through induction of Nrf2 expression [88]. Last but not least, n-3 PUFAs significantly reduce oxidative stressinduced endothelial cell $\mathrm{Ca}^{++}$influx. This effect might be associated, at least in part, with altered lipid composition of membrane lipid rafts [89].

\section{Dietary Walnuts Intake as Source of $\mathbf{n - 3}$ PUFAs to Rejuvenate Helicobacter pylori- Associated Atrophic Gastritis as well as to Augment H. pylori Eradication Rate}

It has been reported that Asian dietary pattern and $H$. pylori infection are typically associated with increased risk of gastric cancer. $H$. pylori, a Gram-negative bacterial pathogen that infects approximately $50 \%$ of the world's population, provokes chronic gastric inflammation, which is considered to be a major risk factor for development of gastric and duodenal ulcers, mucosa-associated lymphoid tissue lymphoma (MALToma), and gastric cancer [2]. Despite the existing debates, there is enough evidence that $H$. pylori infection is strongly associated with gastric cancer, for which it is defined as a class I carcinogen by IARC [90-92]. Mechanistically, gastric epithelial cells respond to $H$. pylori infection by upregulating the expression of proinflammatory genes, which includes the upregulation of COX-2, iNOS, and IL-8 $[93,94]$. With perpetuating gastric inflammation and oxidative stress, $H$. pylori infection gives rise to significant DNA damage, apoptosis, and cell cycle dysregulation, all of which are closely associated with significant oncogenic insults on infected mucosa $[95,96]$. Since gastric cancer is a multistep and multifactorial disease and not every individual infected with H. pylori develops gastric cancer, populationwide eradication strategies are not generally considered as the preventive measures for gastric cancer [97].
H. pylori-related gastric diseases are now considered as infectious diseases and are treated with antibiotic regimens, which are often composed of two antibiotics (amoxicillin and clarithromycin) and a proton pump inhibitor [97, 98]. However, this treatment can fail for several reasons, which include insufficient antibiotic concentration due to mutationacquired resistance, limited antibiotic efficacy in a low gastric $\mathrm{pH}$, and insufficient antibiotic concentration due to a high bacterial load [99]. In addition, existence of viable bacteria in dormant forms that are not accessible to antibiotics and antibiotic-related damage to the mucosal immunity can also be observed. Seeking alternatives to solve the problems of the expense, lower compliance and antibiotic resistance has stretched to nonantimicrobial approaches, which include supplementation with probiotics and other nutrients.

Fresh antioxidant fruits, vegetables, and certain micronutrients such as selenium and vitamin $\mathrm{C}$ can reduce the risk of infection. A food that can inhibit $H$. pylori viability, colonization, and infection can also reduce the risk of cancer. Korean red ginseng, licorice extracts, S-allyl cysteine (SAC) from garlic, probiotics like L. plantarum or Bifidobacillus, and n-3 PUFAs are shown to be effective antibacterials and antimutagenics along with rejuvenating activities in H. pylori infection. Our group extended the supplementation of effective phytoceuticals or phytonutrients to achieve higher eradication rates and possibly prevent the $H$. pyloriassociated gastric cancer [43, 44, 100-102].

Mere eradication yielded limited benefit in some clinical diseases but supplementation with natural products or phytoceuticals rendered higher eradication rates. It is also associated with fewer side effects compared to the triple regimen, higher levels of anti-inflammatory cytokines, and some restorative actions. Our studies showed that SAC supplementation could lead to efficient reduction in inflammation due to potent demethylating mechanism of HDAC inhibition. It can also enforce the regenerative activities along with its antimutagenic action.

Natural phytochemicals with antioxidant, anti-inflammatory, and anticarcinogenic properties that regulate or target specific molecules in gastric carcinogenesis can increase the efficacy of $H$. pylori eradication as an effort to prevent gastric cancer. Nuts and seeds, particularly walnut, are nutritionally dense and rich in vitamin $\mathrm{E}$ and $\mathrm{n}-3$ PUFAs. They are an ample source of dietary fiber, B vitamin, and essential mineral such as magnesium, copper, manganese, calcium, and potassium as well as monounsaturated and polyunsaturated fats, which can potentially lower the LDL cholesterol [103]. Potential health benefits, which have not been scientifically validated, include improved complexion and decreased risk of cancer $[104,105]$.

The fundamental basis of walnuts treatment in $H$. pylori infection is suppression of inflammation and/or inhibition of pathogenic bacteria. There is the possibility that the enhancement of negative regulators of inflammationassociated cytokine by walnuts could also contribute to $H$. pylori eradication. Sliced walnuts contain biotin, vitamin $\mathrm{R}$, manganese, copper, vitamin B12, phosphorus, magnesium, molybdenum, and fiber. Walnut is also high in monounsaturated fats, the same type of health-promoting fat found in 


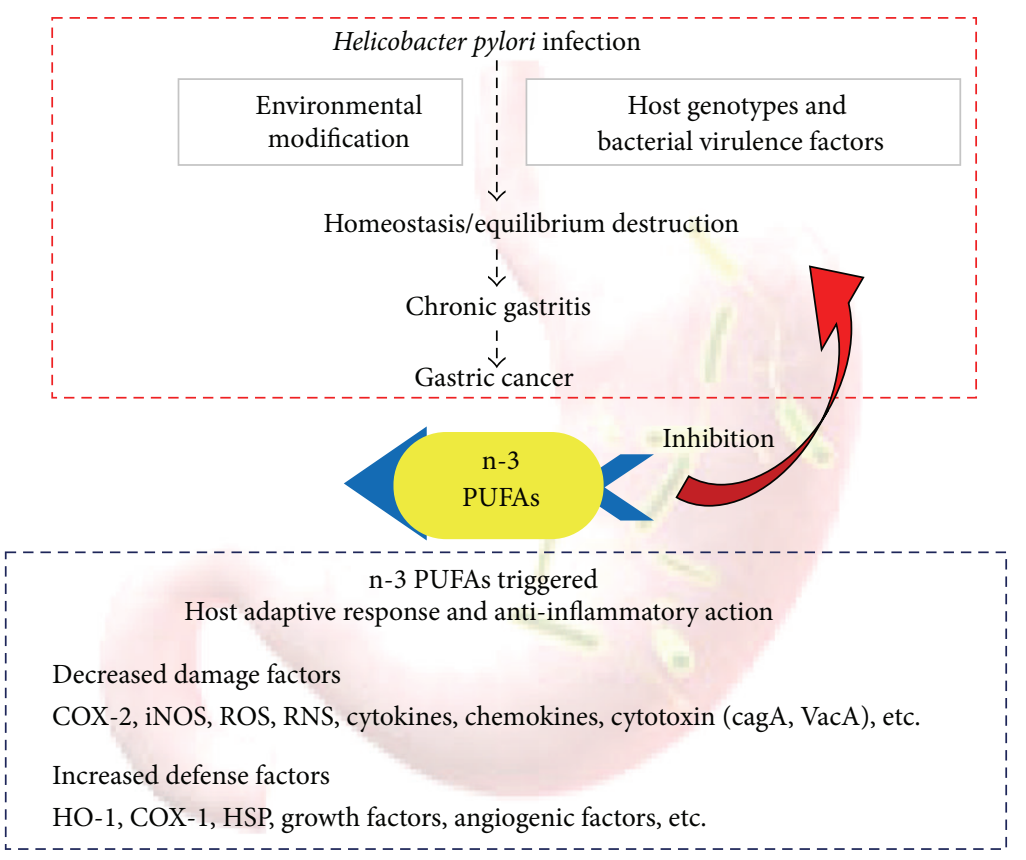

FIgURE 2: Host adoptive and antimutagenic response enhanced with n-3 PUFAs in $H$. pylori infection.

olive oil, which have been associated with reduced risk of heart disease. In addition to the healthy fats and vitamin E, a quarter-cup of walnuts contains $62 \mathrm{mg}$ of magnesium and $162 \mathrm{mg}$ of potassium. These nutritional facts can shed light on the possible beneficial effects of walnuts in H. pylori treatment.

We postulate that high walnut's n-3 PUFAs and vitamin E contents help the treatment and eradication of $H$. pylori infection. $H$. pylori creates a microenvironment to protect itself from gastric acid and host defense systems. It increases the oxidative stress in its colonized areas. It is shown that ROS levels are increased in patients with $H$. pylori infection and that ROS levels are decreased following $H$. pylori eradication. Vitamin E impairs lipid preoxidation pathways and exerts an antioxidant effect. It is also shown that vitamin E concentration is low in the gastric fluid and mucosa of $H$. pylori-infected patients and high after $H$. pylori eradication. These facts suggest a possible benefit from vitamin E supplementation in $H$. pylori infection.

In animal models, short-term therapy with vitamin $\mathrm{E}$ is shown to have restorative effects on $H$. pylori gastritis. It is also shown to have protective effects on $H$. pylori-induced mucosal injury by preventing the accumulation of activated neutrophils. In conclusion, therapeutic doses of vitamin $\mathrm{E}$ decrease the intensity of $H$. pylori infection and neutrophil activity in the antrum. These effects on the bacterial microenvironment could be the reason for the supplementation with antibiotics to increase the eradication rate [106]. We have solid evidence that n-3 PUFAs ameliorated $H$. pyloriinduced gastritis and significantly prevented the gastric cancer. However, some studies showed that magnesium affects the outcome.

\section{Conclusion}

Although $H$. pylori is defined as a class 1 carcinogen by IARC, debate exists on whether the eradication can prevent the associated gastric cancer. Furthermore, host genotype, bacterial virulence factors, and environmental factors can affect the outcome after $H$. pylori infection. Host adaptive responses can modify the carcinogenic influence of $H$. pylori infection (Figure 2). n-3 PUFAs are known to be antioxidant, anti-inflammation, and anticancer. Recently, several investigators have examined the anti-inflammatory, antimicrobial, and rejuvenating effects of n-3 PUFAs on $H$. pylori-induced gastric diseases (Figure 2). There is accumulating evidence that suggests higher consumption of dietary n-3 PUFAs is associated with lower risk of GI cancer development in animal models and human. Recent studies suggest that endogenous n-3 PUFAs delay the progression of stomach cancer and elevating n-3 PUFAs could be an important strategy to delay/prevent gastrointestinal cancer in highrisk patients. This effect is bestowed via several mechanisms mediating cancer prevention such as anti-inflammatory and rejuvenating effects of n-3 PUFAs against carcinogenic $H$. pylori infection. Despite the orchestrated mechanisms of action, maintenance of optimal cellular levels of n-3 PUFAs can be the royalty gatekeeper of $H$. pylori-associated gastric inflammation and cancer. Supplementation with n-3 PUFAs in combination with other antitumor agents can possibly improve the efficacy of GI cancer prevention. Large-scale translational and comprehensive mechanism studies are required to demonstrate the preventive or therapeutic effects of n-3 PUFAs against $H$. pylori-induced gastric diseases. Clinical trials are prerequisites of the decision on the role of chemopreventive agents in $H$. pylori-associated gastric 
cancer. A long-term study that shows the preventive effect of n-3 PUFAs against gastritis and $H$. pylori-induced tumorigenesis will be a prime example of cancer prevention by food.

\section{Conflict of Interests}

The authors declare that there is no conflict of interests regarding the publication of this paper.

\section{Acknowledgments}

This study was supported by a grant from the Ministry of Education and Science Technology (2010-0002052) and High Value-Added Food Technology Development Program, iPET (Korea Institute of Planning and Evaluation for Technology in Food, Agriculture, Forestry and Fisheries), Republic of Korea.

\section{References}

[1] L. E. Wroblewski, R. M. Peek Jr., and K. T. Wilson, "Helicobacter pylori and gastric cancer: factors that modulate disease risk," Clinical Microbiology Reviews, vol. 23, no. 4, pp. 713-739, 2010.

[2] S.-H. Park, N. Kangwan, J.-M. Park, E.-H. Kim, and K. B. Hahm, "Non-microbial approach for Helicobacter pylori as faster track to prevent gastric cancer than simple eradication," World Journal of Gastroenterology, vol. 19, no. 47, pp. 8986-8995, 2013.

[3] V. Conteduca, D. Sansonno, G. Lauletta, S. Russi, G. Ingravallo, and F. Dammacco, "H. pylori infection and gastric cancer: state of the art (Review)," International Journal of Oncology, vol. 42, no. 1, pp. 5-18, 2013.

[4] B. Burlingame, C. Nishida, R. Uauy, and R. Weisell, "Fats and fatty acids in human nutrition: introduction," Annals of Nutrition and Metabolism, vol. 55, no. 1-3, pp. 5-7, 2009.

[5] W. Xin, W. Wei, and X. Li, "Effects of fish oil supplementation on cardiac function in chronic heart failure: a meta-analysis of randomised controlled trials," Heart, vol. 98, no. 22, pp. 1620$1625,2012$.

[6] S. Kar and R. Webel, "Fish oil supplementation \& coronary artery disease: does it help?" Missouri Medicine, vol. 109, no. 2, pp. 142-145, 2012.

[7] E. A. Miles and P. C. Calder, "Influence of marine $n$-3 polyunsaturated fatty acids on immune function and a systematic review of their effects on clinical outcomes in rheumatoid arthritis," British Journal of Nutrition, vol. 107, supplement 2, pp. S171S184, 2012.

[8] I. Rudkowska, "Fish oils for cardiovascular disease: impact on diabetes," Maturitas, vol. 67, no. 1, pp. 25-28, 2010.

[9] R. S. Chapkin, W. Kim, J. R. Lupton, and D. N. McMurray, "Dietary docosahexaenoic and eicosapentaenoic acid: emerging mediators of inflammation," Prostaglandins Leukotrienes and Essential Fatty Acids, vol. 81, no. 2-3, pp. 187-191, 2009.

[10] P. C. Calder, "Immunomodulation by omega-3 fatty acids," Prostaglandins Leukotrienes and Essential Fatty Acids, vol. 77, no. 5-6, pp. 327-335, 2007.

[11] V. C. Vaughan, M.-R. Hassing, and P. A. Lewandowski, "Marine polyunsaturated fatty acids and cancer therapy," British Journal of Cancer, vol. 108, no. 3, pp. 486-492, 2013.
[12] A. J. Cockbain, G. J. Toogood, and M. A. Hull, "Omega-3 polyunsaturated fatty acids for the treatment and prevention of colorectal cancer," Gut, vol. 61, no. 1, pp. 135-149, 2012.

[13] J. A. Stephenson, O. Al-Taan, A. Arshad, B. Morgan, M. S. Metcalfe, and A. R. Dennison, "The multifaceted effects of omega-3 polyunsaturated Fatty acids on the hallmarks of cancer," Journal of Lipids, vol. 2013, Article ID 261247, 13 pages, 2013.

[14] V. C. Pratt, S. Watanabe, E. Bruera et al., "Plasma and neutrophil fatty acid composition in advanced cancer patients and response to fish oil supplementation," British Journal of Cancer, vol. 87, no. 12, pp. 1370-1378, 2002.

[15] S. McClinton, L. E. F. Moffat, D. F. Horrobin, and M. S. Manku, "Abnormalities of essential fatty acid distribution in the plasma phospholipids of patients with bladder cancer," British Journal of Cancer, vol. 63, no. 2, pp. 314-316, 1991.

[16] S. D. Z. V. Leeuwen, M. S. van der Heijden, T. Rietveld et al., "Fatty acid composition of plasma lipids in patients with pancreatic, lung and oesophageal cancer in comparison with healthy subjects," Clinical Nutrition, vol. 21, no. 3, pp. 225-230, 2002.

[17] M. R. Moore and R. A. King, "Effects of omega-3 fatty acids on progestin stimulation of invasive properties in breast cancer," Hormones and Cancer, vol. 3, no. 5-6, pp. 205-217, 2012.

[18] N. Sawada, M. Inoue, M. Iwasaki et al., "Consumption of n-3 fatty acids and fish reduces risk of hepatocellular carcinoma," Gastroenterology, vol. 142, no. 7, pp. 1468-1475, 2012.

[19] Z. Gu, J. Suburu, H. Chen, and Y. Q. Chen, "Mechanisms of omega-3 polyunsaturated fatty acids in prostate cancer prevention," BioMed Research International, vol. 2013, Article ID 824563, 10 pages, 2013.

[20] E. Fasano, S. Serini, E. Piccioni, I. Innocenti, and G. Calviello, "Chemoprevention of lung pathologies by dietary n-3 polyunsaturated fatty acids," Current Medicinal Chemistry, vol. 17, no. 29, pp. 3358-3376, 2010.

[21] M. Spite, "Deciphering the role of n-3 polyunsaturated fatty acid-derived lipid mediators in health and disease," Proceedings of the Nutrition Society, vol. 72, no. 4, pp. 441-450, 2013.

[22] J. W. Fetterman Jr. and M. M. Zdanowicz, "Therapeutic potential of n-3 polyunsaturated fatty acids in disease," American Journal of Health-System Pharmacy, vol. 66, no. 13, pp. 11691179, 2009.

[23] P. C. Calder, " $n-3$ polyunsaturated fatty acids, inflammation, and inflammatory diseases," The American Journal of Clinical Nutrition, vol. 83, no. 6, supplement, pp. 1505S-1519S, 2006.

[24] P. C. Calder, "Dietary modification of inflammation with lipids," Proceedings of the Nutrition Society, vol. 61, no. 3, pp. 345-358, 2002.

[25] A. P. Simopoulos, "Omega-3 fatty acids in inflammation and autoimmune diseases," Journal of the American College of Nutrition, vol. 21, no. 6, pp. 495-505, 2002.

[26] C. M. Yates, P. C. Calder, and G. Ed Rainger, "Pharmacology and therapeutics of omega-3 polyunsaturated fatty acids in chronic inflammatory disease," Pharmacology and Therapeutics, vol. 141, no. 3, pp. 272-282, 2014.

[27] J. M. Kremer, " $n-3$ fatty acid supplements in rheumatoid arthritis," The American Journal of Clinical Nutrition, vol. 71, no. 1, supplement, pp. 349S-351S, 2000.

[28] R. J. Goldberg and J. Katz, "A meta-analysis of the analgesic effects of omega-3 polyunsaturated fatty acid supplementation for inflammatory joint pain," Pain, vol. 129, no. 1-2, pp. 210-223, 2007. 
[29] N. Kangwan, J. M. Park, and K. B. Hahm, "Development of GIsafe NSAID; progression from the bark of willow tree to modern pharmacology," Current Opinion in Pharmacology, vol. 19, pp. 17-23, 2014.

[30] A. B. Hawthorne, T. K. Daneshmend, C. J. Hawkey a et al., "Treatment of ulcerative colitis with fish oil supplementation: a prospective 12 month randomised controlled trial," Gut, vol. 33, no. 7, pp. 922-928, 1992.

[31] T. Shimizu, T. Fujii, R. Suzuki et al., "Effects of highly purified eicosapentaenoic acid on erythrocyte fatty acid composition and leukocyte and colonic mucosa leukotriene B4 production in children with ulcerative colitis," Journal of Pediatric Gastroenterology \& Nutrition, vol. 37, no. 5, pp. 581-585, 2003.

[32] B. G. Feagan, W. J. Sandborn, U. Mittmann et al., "Omega-3 free fatty acids for the maintenance of remission in crohn disease: the EPIC randomized controlled trials," The Journal of the American Medical Association, vol. 299, no. 14, pp. 16901697, 2008.

[33] A. Yokoyama, T. Hamazaki, A. Ohshita et al., "Effect of aerosolized docosahexaenoic acid in a mouse model of atopic asthma," International Archives of Allergy and Immunology, vol. 123, no. 4, pp. 327-332, 2000.

[34] S. Bilal, O. Haworth, L. Wu, K. H. Weylandt, B. D. Levy, and J. X. Kang, "Fat-1 transgenic mice with elevated omega-3 fatty acids are protected from allergic airway responses," Biochimica et Biophysica Acta, vol. 1812, no. 9, pp. 1164-1169, 2011.

[35] M. Hirafuji, T. Machida, N. Hamaue, and M. Minami, "Cardiovascular protective effects of n-3 polyunsaturated fatty acids with special emphasis on docosahexaenoic acid," Journal of Pharmacological Sciences, vol. 92, no. 4, pp. 308-316, 2003.

[36] S. Xia, Y. Lu, J. Wang et al., "Melanoma growth is reduced in fat1 transgenic mice: impact of omega-6/omega-3 essential fatty acids," Proceedings of the National Academy of Sciences of the United States of America, vol. 103, no. 33, pp. 12499-12504, 2006.

[37] A. Leaf, C. M. Albert, M. Josephson et al., "Prevention of fatal arrhythmias in high-risk subjects by fish oil n-3 fatty acid intake," Circulation, vol. 112, no. 18, pp. 2762-2768, 2005.

[38] A. Gerbi, J.-M. Maixent, J.-L. Ansaldi et al., "Fish oil supplementation prevents diabetes-induced nerve conduction velocity and neuroanatomical changes in rats," Journal of Nutrition, vol. 129, no. 1, pp. 207-213, 1999.

[39] T. C. Coste, A. Gerbi, P. Vague, G. Pieroni, and D. Raccah, "Neuroprotective effect of docosahexaenoic acid-enriched phospholipids in experimental diabetic neuropathy," Diabetes, vol. 52, no. 10, pp. 2578-2585, 2003.

[40] G. P. Lim, F. Calon, T. Morihara et al., "A diet enriched with the omega-3 fatty acid docosahexaenoic acid reduces amyloid burden in an aged Alzheimer mouse model," The Journal of Neuroscience, vol. 25, no. 12, pp. 3032-3040, 2005.

[41] P. C. Calder, "Marine omega-3 fatty acids and inflammatory processes: effects, mechanisms and clinical relevance," Biochimica et Biophysica Acta-Molecular and Cell Biology of Lipids, 2014.

[42] D. Schottenfeld and J. Beebe-Dimmer, "Chronic inflammation: a common and important factor in the pathogenesis of neoplasia," CA: A Cancer Journal for Clinicians, vol. 56, no. 2, pp. 69-83, 2006.

[43] M. Correia, V. Michel, A. A. Matos et al., "Docosahexaenoic acid inhibits Helicobacter pylori growth in vitro and mice gastric mucosa colonization," PLoS ONE, vol. 7, no. 4, Article ID e35072, 2012.
[44] L. Thompson, A. Cockayne, and R. C. Spiller, "Inhibitory effect of polyunsaturated fatty acids on the growth of Helicobacter pylori: a possible explanation of the effect of diet on peptic ulceration," Gut, vol. 35, no. 11, pp. 1557-1561, 1994.

[45] A. Mohammed, N. B. Janakiram, M. Brewer et al., "Endogenous n-3 polyunsaturated fatty acids delay progression of pancreatic ductal adenocarcinoma in Fat-1-p48 ${ }^{\mathrm{Cre} /+}$-LSL-Kras ${ }^{G 12 D /+}$ mice," Neoplasia, vol. 14, no. 12, pp. 1249-1259, 2012.

[46] K. Kuriki, K. Wakai, K. Matsuo et al., "Gastric cancer risk and erythrocyte composition of docosahexaenoic acid with antiinflammatory effects," Cancer Epidemiology Biomarkers and Prevention, vol. 16, no. 11, pp. 2406-2415, 2007.

[47] C. Otto, U. Kaemmerer, B. Illert et al., "Growth of human gastric cancer cells in nude mice is delayed by a ketogenic diet supplemented with omega-3 fatty acids and medium-chain triglycerides," BMC Cancer, vol. 8, article 122, 2008.

[48] M.-H. Wu, Y.-T. Tsai, K.-T. Hua, K.-C. Chang, M.-L. Kuo, and M.-T. Lin, "Eicosapentaenoic acid and docosahexaenoic acid inhibit macrophage-induced gastric cancer cell migration by attenuating the expression of matrix metalloproteinase 10," Journal of Nutritional Biochemistry, vol. 23, no. 11, pp. 1434-1439, 2012.

[49] Q. Wu, J. C. Yu, Y. Q. Liu, W. M. Kang, and W. D. Guo, "Effect of combination of docosahexaenoic acid and fluorouracil on human gastric carcinoma cell strain MGC803," Zhongguo Yi Xue Ke Xue Yuan Xue Bao, vol. 32, no. 1, pp. 65-70, 2010.

[50] J. H. Yu, S.-G. Kang, U.-Y. Jung, C.-H. Jun, and H. Kim, "Effects of omega-3 fatty acids on apoptosis of human gastric epithelial cells exposed to silica-immobilized glucose oxidase," Annals of the New York Academy of Sciences, vol. 1171, pp. 359-364, 2009.

[51] S. E. Lee, J. W. Lim, and H. Kim, "Activator protein-1 mediates docosahexaenoic acid-induced apoptosis of human gastric cancer cells," Annals of the New York Academy of Sciences, vol. 1171, pp. 163-169, 2009.

[52] C. H. MacLean, S. J. Newberry, W. A. Mojica et al., "Effects of omega-3 fatty acids on cancer risk: a systematic review," The Journal of the American Medical Association, vol. 295, no. 4, pp. 403-415, 2006.

[53] A. Nakaya, H. Wakabayashi, L. Imamura et al., "Helicobacter pylori alters n-6 fatty acid metabolism and prostaglandin E2 synthesis in rat gastric mucosal cells," Journal of Gastroenterology and Hepatology, vol. 16, no. 11, pp. 1197-1205, 2001.

[54] D. Hollander and A. Tarnawski, "Is there a role for dietary essential fatty acids in gastroduodenal mucosal protection?" Journal of Clinical Gastroenterology, vol. 13, no. 1, pp. S72-S74, 1991.

[55] V. Manjari and U. N. Das, "Effect of polyunsaturated fatty acids on dexamethasone-induced gastric mucosal damage," Prostaglandins Leukotrienes and Essential Fatty Acids, vol. 62, no. 2, pp. 85-96, 2000.

[56] A. E. Duggan, J. C. Atherton, A. Cockayne et al., "Clarification of the link between polyunsaturated fatty acids and Helicobacter pylori-associated duodenal ulcer disease: a dietary intervention study," British Journal of Nutrition, vol. 78, no. 4, pp. 515-522, 1997.

[57] S. E. Lee, J. W. Lim, J. M. Kim, and H. Kim, "Anti-inflammatory mechanism of polyunsaturated fatty acids in Helicobacter pylori-infected gastric epithelial cells," Mediators of Inflammation, vol. 2014, Article ID 128919, 12 pages, 2014.

[58] M. Correia, V. Michel, H. Osório et al., "Crosstalk between Helicobacter pylori and gastric epithelial cells is impaired by 
docosahexaenoic acid," PLoS ONE, vol. 8, no. 4, Article ID e60657, 2013.

[59] H. L. Woodworth, S. J. McCaskey, D. M. Duriancik et al., "Dietary fish oil alters $\mathrm{T}$ lymphocyte cell populations and exacerbates disease in a mouse model of inflammatory colitis," Cancer Research, vol. 70, no. 20, pp. 7960-7969, 2010.

[60] L. M. Butler and M. C. Yu, "Fish oil exacerbates colitis in SMAD3 mice," Cancer Research, vol. 71, no. 1, pp. 287-288, 2011.

[61] E. A. Gurzell, H. Teague, M. Harris, J. Clinthorne, S. R. Shaikh, and J. I. Fenton, "DHA-enriched fish oil targets B cell lipid microdomains and enhances ex vivo and in vivo B cell function," Journal of Leukocyte Biology, vol. 93, no. 4, pp. 463470, 2013.

[62] S. R. Shaikh, B. D. Rockett, M. Salameh, and K. Carraway, "Docosahexaenoic acid modifies the clustering and size of lipid rafts and the lateral organization and surface expression of MHC class I of EL4 cells," The Journal of Nutrition, vol. 139, no. 9, pp. 1632-1639, 2009.

[63] B. D. Rockett, H. Teague, M. Harris et al., "Fish oil increases raft size and membrane order of B cells accompanied by differential effects on function," Journal of Lipid Research, vol. 53, no. 4, pp. 674-685, 2012.

[64] R. Meier, A. Wettstein, J. Drewe, and H. R. Geiser, "Fish oil (Eicosapen) is less effective than metronidazole, in combination with pantoprazole and clarithromycin, for Helicobacter pylori eradication," Alimentary Pharmacology and Therapeutics, vol. 15, no. 6, pp. 851-855, 2001.

[65] H. A. Marsman, W. de Graaf, M. Heger et al., "Hepatic regeneration and functional recovery following partial liver resection in an experimental model of hepatic steatosis treated with omega-3 fatty acids," British Journal of Surgery, vol. 100, no. 5, pp. 674-683, 2013.

[66] H. F. Turk, J. M. Monk, Y.-Y. Fan, E. S. Callaway, B. Weeks, and R. S. Chapkin, "Inhibitory effects of omega-3 fatty acids on injury-induced epidermal growth factor receptor transactivation contribute to delayed wound healing," American Journal of Physiology-Cell Physiology, vol. 304, no. 9, pp. C905-C917, 2013.

[67] L. Gao, D. Faibish, G. Fredman et al., "Resolvin E1 and chemokine-like receptor 1 mediate bone preservation," Journal of Immunology, vol. 190, no. 2, pp. 689-694, 2013.

[68] J. F. Tarlton, L. J. Wilkins, M. J. Toscano, N. C. Avery, and L. Knott, "Reduced bone breakage and increased bone strength in free range laying hens fed omega-3 polyunsaturated fatty acid supplemented diets," Bone, vol. 52, no. 2, pp. 578-586, 2013.

[69] S. Bohr, S. J. Patel, D. Sarin, D. Irimia, M. L. Yarmush, and F. Berthiaume, "Resolvin D2 prevents secondary thrombosis and necrosis in a mouse burn wound model," Wound Repair and Regeneration, vol. 21, no. 1, pp. 35-43, 2013.

[70] W. Zhuang, G. Wang, L. Li, G. Lin, and Z. Deng, "Omega-3 polyunsaturated fatty acids reduce vascular endothelial growth factor production and suppress endothelial wound repair," Journal of Cardiovascular Translational Research, vol. 6, no. 2, pp. 287-293, 2013.

[71] A. D. Widgerow, "Cellular resolution of inflammationcatabasis," Wound Repair and Regeneration, vol. 20, no. 1, pp. 2-7, 2012.

[72] S. J. Gladman, W. Huang, S.-N. Lim et al., "Improved outcome after peripheral nerve injury in mice with increased levels of endogenous omega-3 polyunsaturated fatty acids," The Journal of Neuroscience, vol. 32, no. 2, pp. 563-571, 2012.
[73] B. Ekçi, I. Karabicak, P. Atukeren, E. Altinli, K. Tomaoglu, and I. Tasci, "The effect of omega-3 fatty acid and ascorbic acid on healing of ischemic colon anastomoses," Annali Italiani di Chirurgia, vol. 82, no. 6, pp. 475-479, 2011.

[74] Y.-D. Qiu, S. Wang, Y. Yang, and X.-P. Yan, "Omega-3 polyunsaturated fatty acids promote liver regeneration after $90 \%$ hepatectomy in rats," World Journal of Gastroenterology, vol. 18, no. 25, pp. 3288-3295, 2012.

[75] J. W. Alexander, H. Saito, O. Trocki, and C. K. Ogle, “The importance of lipid type in the diet after burn injury," Annals of Surgery, vol. 204, no. 1, pp. 1-8, 1986.

[76] M. S. Cortina, J. He, N. Li, N. G. Bazan, and H. E. P. Bazan, "Neuroprotectin D1 synthesis and corneal nerve regeneration after experimental surgery and treatment with PEDF plus DHA," Investigative Ophthalmology and Visual Science, vol. 51, no. 2, pp. 804-810, 2010.

[77] O. Chow and A. Barbul, "Immunonutrition: role in wound healing and tissue regeneration," Advances in Wound Care, vol. 3, no. 1, pp. 46-53, 2014.

[78] P. Martin and S. J. Leibovich, "Inflammatory cells during wound repair: the good, the bad and the ugly," Trends in Cell Biology, vol. 15, no. 11, pp. 599-607, 2005.

[79] L. Lluís, N. Taltavull, M. Muñoz-Cortés et al., "Protective effect of the omega-3 polyunsaturated fatty acids: Eicosapentaenoic acid/Docosahexaenoic acid 1:1 ratio on cardiovascular disease risk markers in rats," Lipids in Health and Disease, vol. 12, no. 1, article 140, 2013.

[80] N. Avramovic, V. Dragutinovic, D. Krstic et al., “The effecects of omega 3 fatty acid supplementation on brain tissue oxidative status in aged Wistar rats," Hippokratia, vol. 16, no. 3, pp. 241245, 2012.

[81] R. Crupi, A. Marino, and S. Cuzzocrea, "n-3 fatty acids: role in neurogenesis and neuroplasticity," Current Medicinal Chemistry, vol. 20, no. 24, pp. 2953-2963, 2013.

[82] S. R. Shaikh, "Diet-induced docosahexaenoic acid non-raft domains and lymphocyte function," Prostaglandins Leukotrienes and Essential Fatty Acids, vol. 82, no. 4-6, pp. 159-164, 2010.

[83] G. Calviello, S. Serini, and E. Piccioni, "n-3 polyunsaturated fatty acids and the prevention of colorectal cancer: molecular mechanisms involved," Current Medicinal Chemistry, vol. 14, no. 29, pp. 3059-3069, 2007.

[84] B. D. Rockett, A. Franklin, M. Harris, H. Teague, A. Rockett, and S. R. Shaikh, "Membrane raft organization is more sensitive to disruption by (n-3) PUFA than nonraft organization in EL4 and B cells," Journal of Nutrition, vol. 141, no. 6, pp. 1041-1048, 2011.

[85] J. Kim, Y.-N. Cha, and Y.-J. Surh, "A protective role of nuclear factor-erythroid 2-related factor-2 (Nrf2) in inflammatory disorders," Mutation Research, vol. 690, no. 1-2, pp. 12-23, 2010.

[86] L. Gao, J. Wang, K. R. Sekhar et al., "Novel $n-3$ fatty acid oxidation products activate Nrf2 by destabilizing the association between Keapl and Cullin3," The Journal of Biological Chemistry, vol. 282, no. 4, pp. 2529-2537, 2007.

[87] Y.-C. Yang, C.-K. Lii, Y.-L. Wei et al., "Docosahexaenoic acid inhibition of inflammation is partially via cross-talk between Nrf2/heme oxygenase 1 and IKK/NF-kappaB pathways," Journal of Nutritional Biochemistry, vol. 24, no. 1, pp. 204-212, 2013.

[88] H. Wang, T. O. Khor, C. L. L. Saw et al., "Role of Nrf2 in suppressing LPS-induced inflammation in mouse peritoneal macrophages by polyunsaturated fatty acids docosahexaenoic acid and eicosapentaenoic acid," Molecular Pharmaceutics, vol. 7, no. 6, pp. 2185-2193, 2010. 
[89] S. Ye, L. Tan, J. Ma, Q. Shi, and J. Li, "Polyunsaturated docosahexaenoic acid suppresses oxidative stress induced endothelial cell calcium influx by altering lipid composition in membrane caveolar rafts," Prostaglandins Leukotrienes \& Essential Fatty Acids, vol. 83, no. 1, pp. 37-43, 2010.

[90] N. Uemura, S. Okamoto, S. Yamamoto et al., "Helicobacter pylori infection and the development of gastric cancer," New England Journal of Medicine, vol. 345, no. 11, pp. 784-789, 2001.

[91] T. Watanabe, M. Tada, H. Nagi, S. Sasaki, and M. Nakao, "Helicobacter pylori infection induces gastric cancer in Mongolian gerbils," Gastroenterology, vol. 115, no. 3, pp. 642-648, 1998.

[92] E. J. Kuipers, J. C. Thijs, and H. P. M. Festen, "The prevalence of Helicobacter pylori in peptic ulcer disease," Alimentary Pharmacology and Therapeutics, vol. 9, supplement 2, pp. 59-69, 1995.

[93] K. B. Hahm, K. J. Lee, J. H. Kim, S. W. Cho, and M. H. Chung, "Helicobacter pylori infection, oxidative DNA damage, gastric carcinogenesis, and reversibility by rebamipide," Digestive Diseases and Sciences, vol. 43, no. 9, supplement, pp. 72S-77S, 1998.

[94] E. E. Mannick, L. E. Bravo, G. Zarama et al., "Inducible nitric oxide synthase, nitrotyrosine, and apoptosis in Helicobacter pylori gastritis: effect of antibiotics and antioxidants," Cancer Research, vol. 56, no. 14, pp. 3238-3243, 1996.

[95] E. J. O'Rourke, C. Chevalier, A. V. Pinto et al., "Pathogen DNA as target for host-generated oxidative stress: role for repair of bacterial DNA damage in Helicobacter pylori colonization," Proceedings of the National Academy of Sciences of the United States of America, vol. 100, no. 5, pp. 2789-2794, 2003.

[96] D. Bagchi, T. R. McGinn, X. Ye et al., "Helicobacter pyloriinduced oxidative stress and DNA damage in a primary culture of human gastric mucosal cells," Digestive Diseases and Sciences, vol. 47, no. 6, pp. 1405-1412, 2002.

[97] S. K. Lam and N. J. Talley, "Report of the 1997 Asia Pacific Consensus Conference on the management of Helicobacter pylori infection," Journal of Gastroenterology and Hepatology, vol. 13, no. 1, pp. 1-12, 1998.

[98] "Current European concepts in the management of Helicobacter pylori infection. The Maastricht consensus report. European Helicobacter pylori study group," Gut, vol. 41, no. 1, pp. 8-13, 1997.

[99] F. Mégraud and H. Lamouliatte, "Review article: the treatment of refractory Helicobacter pylori infection," Alimentary Pharmacology \& Therapeutics, vol. 17, no. 11, pp. 1333-1343, 2003.

[100] S. Szabo, J. S. Trier, A. Brown, J. Schnoor, H. D. Homan, and J. C. Bradford, "A quantitative method for assessing the extent of experimental gastric erosions and ulcers," Journal of Pharmacological Methods, vol. 13, no. 1, pp. 59-66, 1985.

[101] A. Asadipour, N. Edraki, M. Nakhjiri et al., "Anti-Helicobacter pylori activity and structure-activity relationship study of 2-alkylthio-5-(nitroaryl)-1,3,4-thiadiazole derivatives," Iranian Journal of Pharmaceutical Research, vol. 12, no. 3, pp. 281-287, 2013.

[102] Y. Minami, H. Miyata, Y. Doki et al., "omega-3 Fatty acidcontaining diet (Racol) reduces toxicity of chemoradiation therapy for patients with esophageal cancer," Gan To Kagaku Ryoho, vol. 35, no. 3, pp. 437-440, 2008.

[103] P. M. Kris-Etherton, "Walnuts decrease risk of cardiovascular disease: a summary of efficacy and biologic mechanisms," Journal of Nutrition, vol. 144, no. 4, supplement, pp. 547S-554S, 2014.

[104] W. E. Hardman, "Diet components can suppress inflammation and reduce cancer risk," Nutrition Research and Practice, vol. 8, no. 3, pp. 233-240, 2014.
[105] W. E. Hardman, "Walnuts have potential for cancer prevention and treatment in mice," Journal of Nutrition, vol. 144, no. 4, supplement, pp. 555S-560S, 2014.

[106] M. Sezikli, Z. A. Çetinkaya, F. Güzelbulut et al., "Effects of alpha tocopherol and ascorbic acid on Helicobacter pylori colonization and the severity of gastric inflammation," Helicobacter, vol. 17, no. 2, pp. 127-132, 2012. 

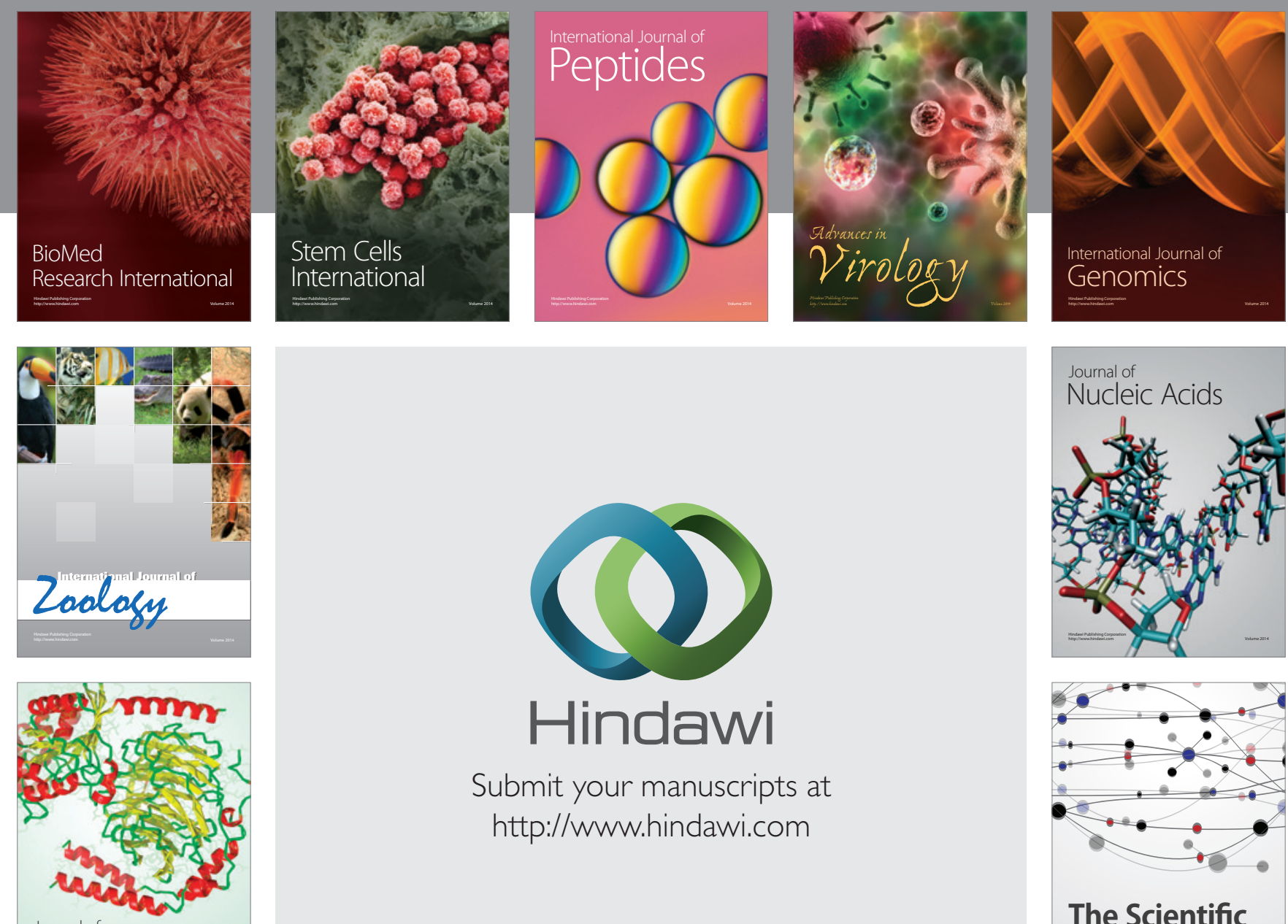

Submit your manuscripts at

http://www.hindawi.com

Journal of
Signal Transduction
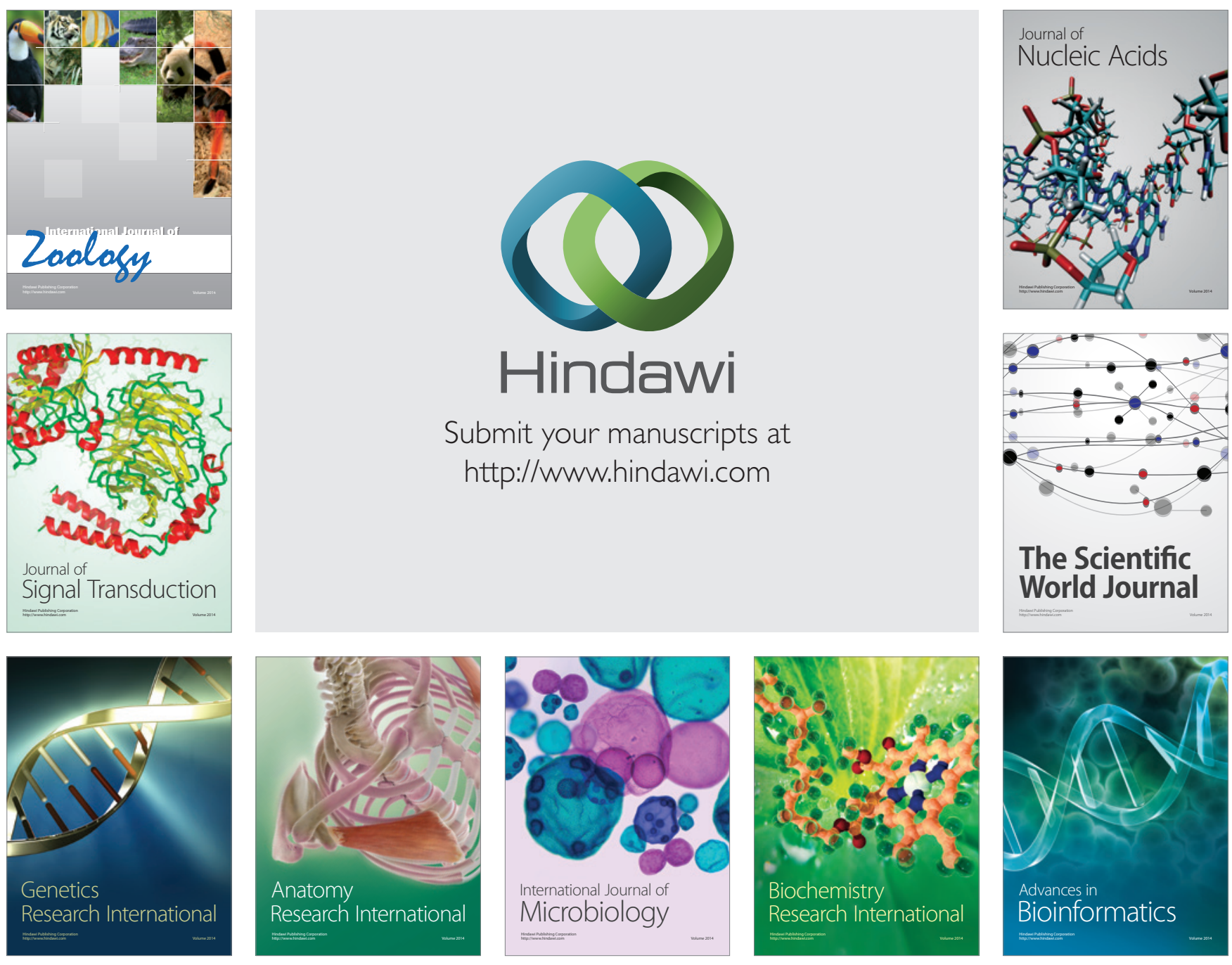

The Scientific World Journal
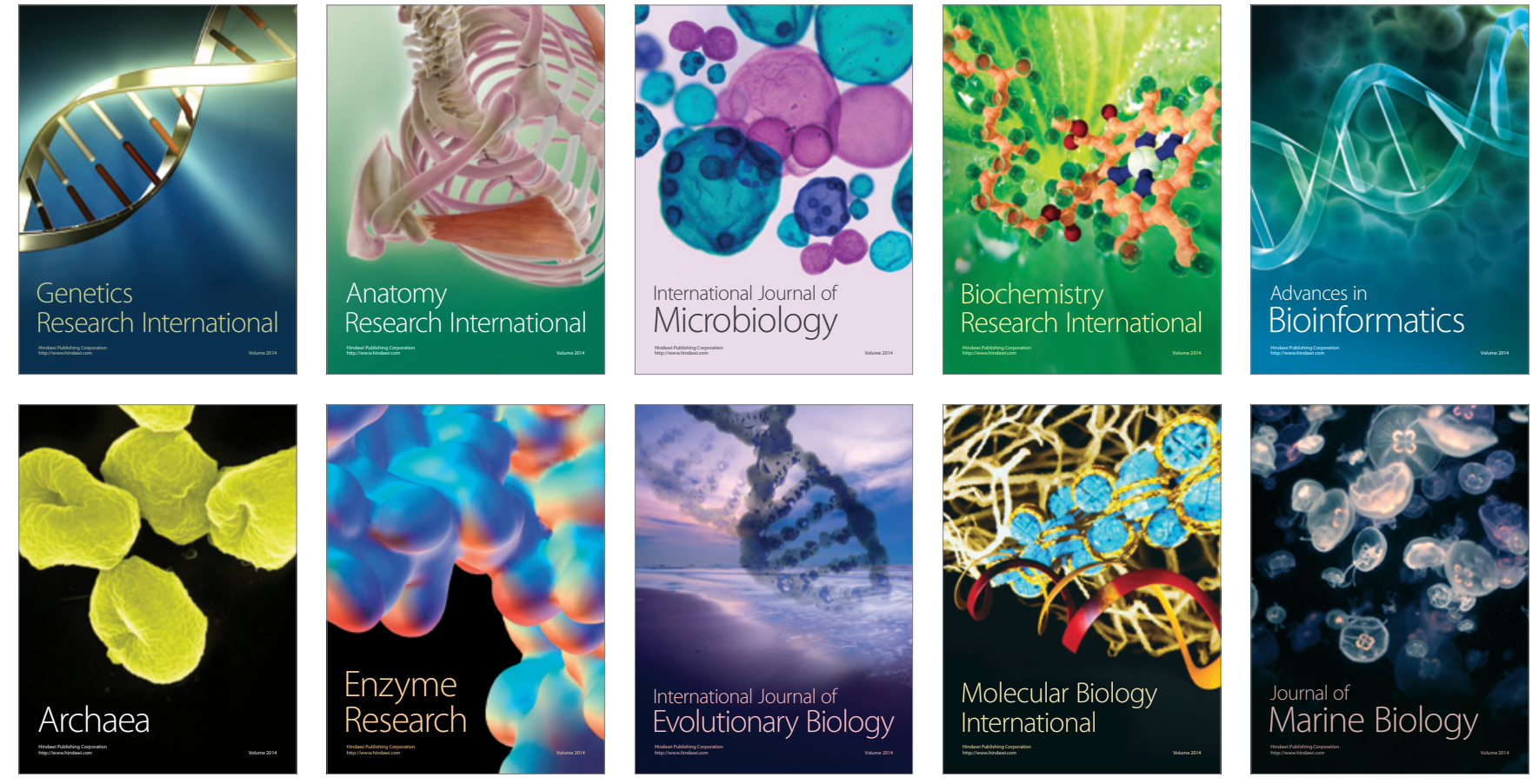